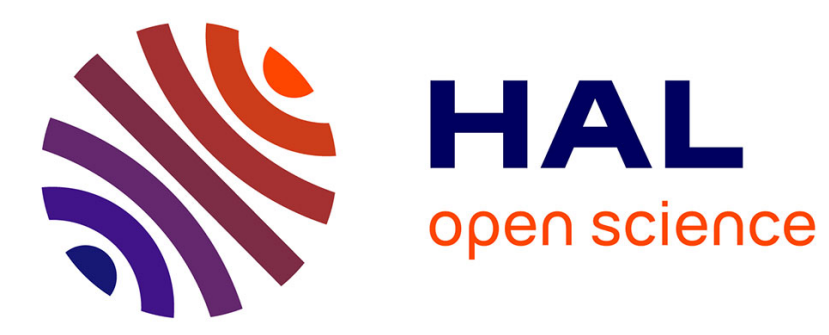

\title{
DIRECTIVITY PATTERNS OF THE ACOUSTIC FIELD RADIATED FROM A SEMI-INFINITE UNFLANGED HARD WALLED CIRCULAR DUCT
}

A. Snakowska

\section{- To cite this version:}

A. Snakowska. DIRECTIVITY PATTERNS OF THE ACOUSTIC FIELD RADIATED FROM A SEMI-INFINITE UNFLANGED HARD WALLED CIRCULAR DUCT. Journal de Physique IV Proceedings, 1992, 02 (C1), pp.C1-653-C1-656. 10.1051/jp4:19921141 . jpa-00251099

HAL Id: jpa-00251099

https://hal.science/jpa-00251099

Submitted on 1 Jan 1992

HAL is a multi-disciplinary open access archive for the deposit and dissemination of scientific research documents, whether they are published or not. The documents may come from teaching and research institutions in France or abroad, or from public or private research centers.
L'archive ouverte pluridisciplinaire HAL, est destinée au dépôt et à la diffusion de documents scientifiques de niveau recherche, publiés ou non, émanant des établissements d'enseignement et de recherche français ou étrangers, des laboratoires publics ou privés. 


\title{
DIRECTIVITY PATTERNS OF THE ACOUSTIC FIELD RADIATED FROM A SEMI-INFINITE UNFLANGED HARD WALLED CIRCULAR DUCT
}

\section{A. SNAKOWSKA}

Institute of Physics, Pedagogical University of Rzeszów, ul Rejtana 16a, PL-35310 Rzeszów, Poland

\begin{abstract}
The theory of axi-symmetric wave that propagates to the duct outlet and radiates outside has been reviewed and applied to analyse the radiation characteristics in the far field. In general, the axi-symmetric wave that can propagate without damping along the semi-infinite hard walled duct is the superposition of all radial modes allowed at the fixed diffraction parameter. The mathematical tool used to obtain the results was the saddle point method applied to the exact formula for the velocity potential. The diffraction phenomena have been taken into account. Computed radiation characteristics of pressure and intensity directivity functions as well as power-gain function have been obtained for the diffraction parameter changing in the range 0-15. Some of the examples are presented on graphs.
\end{abstract}

Sommaire. - Nous a vons développé la théorie d'une onde dans un conduit circulaire et là appliquée à calculer la directivité de champ acustique lointain dans l'éspace exterieur. En général, l'onde axial-symmetrique dans un conduit cylindrique a vec les parois rigides est la superposition des touts les modes admissibles pour la valeur donnée de parametre de diffraction. Pour obtenir les resultats on a appliquée la méthode de la selle à la formule exacte pour le potentiel acustique. Les phénomènes de diffraction ont été pris en considération. Nous avons calculé les caractéristiques de directivité de pression, d'intensité et aussi de la fonction de gain pour les valeurs de parametre de diffraction de 0 à 15 . Quelques exemples sont presentés sur les graphiques.

\section{Introduction}

Ducts, pipes and tubes are called wave-guides because they carry the acoustic energy very efficiently. This feature is sometimes very useful (e.g. in sending signals at long distances) but sometimes causes an undesirable noise outside (e.g. in the aircraft transport). A necessity often arises to damp this harmful noise so the knowledge of energy distribution in the field outside the duct could be very helpful. That causes the investigation of acoustic pressure, intensity, power-gain function to be of great, not only theoretical, but also practical importance.

The problem of sound radiating from the duct has, by now, been considered by many authors under different simplifying assumptions:

- the incident and reflected waves are plane waves,

- the incident wave is a plane wave, but due to diffraction phenomena the reflected wave is a superposition of all modes allowed,

- the incident wave is an arbitrary but single mode, the diffraction effects are considered as above. 
The first case presupposes that the diffraction parameter $k a<3.83, k$ being the wave number and $a$ - the duct radius. At a fixed $k a$ the highest radial mode which can propagate along the duct fulfils the condition $\mu_{N}<k a<\mu_{N+1}$, where $\mu_{N}$ is the $N$-th root of the Bessel function $J_{1}\left(\mu_{1}=\right.$ $3.83, \mu_{2}=7.02, \mu_{3}=10.14$ ). The frequency below which a certain mode cannot propagate is called the cut-off frequency. For the diffraction parameter $k a>3.83$ the wave in the duct is, in practice, a superposition of all modes allowed [1].

The purpose of this paper is to discuss radiation directivity characteristics for an arbitrary axi-symmetric incident wave, which propagates to the open end, where it is partly reflected and partly radiated outside.

\section{Basic formulae}

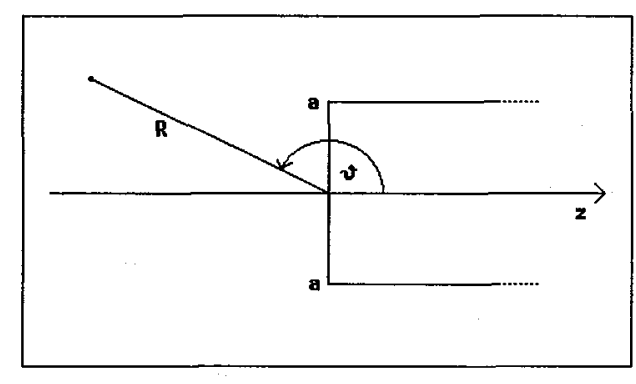

Fig. 1

The geometry of the duct is presented on Fig.1. Assuming an axi-symmetric excitation we would describe the problem using polar coordinates $(R, \vartheta)$. If we express the velocity potential of a single $l$-th mode of unit amplitude in the form obtained by applying the saddle point method to the exact formula for potential $[2,3]$

$$
\Phi_{l}(R, \vartheta)=d_{l}(\vartheta) \frac{\exp (i k R)}{R}
$$

$d_{l}(\vartheta)$ being the directivity coefficient, the potential of incident wave can be written as

$$
\Phi(R, \vartheta)=\sum_{l=0}^{N} A_{l} \Phi_{l}(R, \vartheta),
$$

$A_{l}$ being complex amplitude. In the present paper we limit ourselves to the infinite distance approximation. The detailed investigations are reported in [3].

Pressure directivity function $s^{p}(\vartheta, \varphi)$ can be defined as a coefficient comparing the pressure in given direction with that of a point source of equal power output. After these remarks we can write the formula in the following form

$$
s^{p}(\vartheta)=\left|\sum_{l=0}^{N} A_{l} d_{l}(\vartheta)\right| .
$$

Intensity directivity function is, according to the definition, equal to

$$
s^{I}(\vartheta, \varphi)=\frac{K^{I}(\vartheta, \varphi)}{P_{0}}
$$

where $K^{I}$ and $P_{0}$ denote power radiated in a unit solid angle by a source under consideration and by a point source of the same output, respectively. In this case, after some calculations, we get the following result

$$
s^{I}(\vartheta)=\left|\sum_{l=0}^{N} A_{l} d_{l}(\vartheta)\right|^{2} .
$$

The power-gain function indicates what part of the energy has been radiated into a unit solid angle

$$
G(\vartheta)=\frac{K^{I}(\vartheta)}{P^{\mathrm{rad}} / 4 \pi}
$$


$P^{\text {rad }}$ being the total energy radiated outside the duct. The final formula gets the form

$$
G(\vartheta)=\frac{4\left|\sum_{l=0}^{N} A_{l} d_{l}(\vartheta)\right|^{2}}{k a^{2} \sum_{l=0}^{N}\left|A_{l}\right|^{2} \gamma_{l}\left(1-r_{l}\right)},
$$
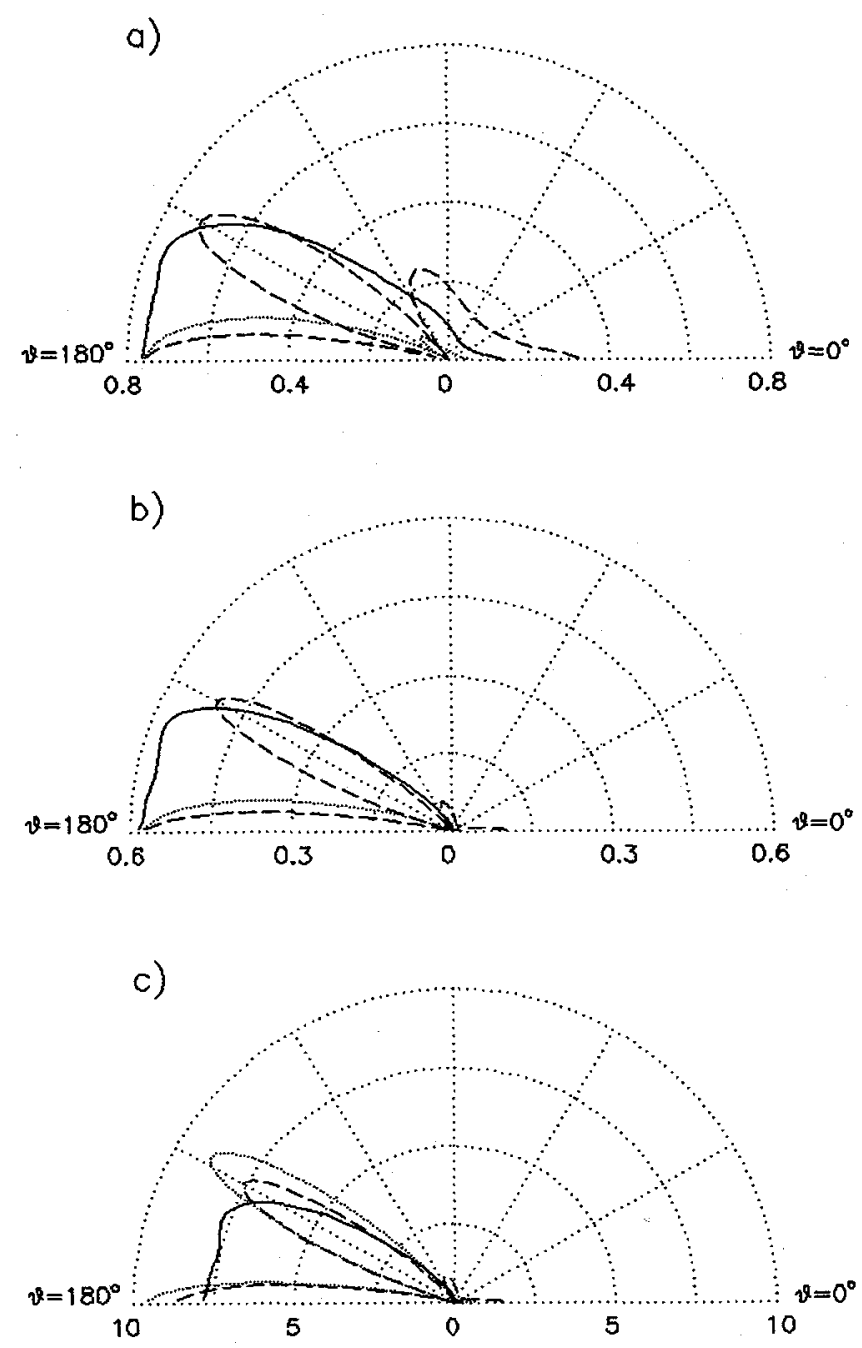

Fig.2 a) Pressure directivity patterns for $k a=8$ and radial modes amplitudes being equal to: $A_{0}=-0.21+0.32 i, A_{1}=1, A_{2}=-0.64 i$ (solid line), $A_{0}=0.38, A_{1}=1, A_{2}=0.64$ (dashed line), $A_{0}=0.38, A_{1}=0, A_{2}=0$ (dotted line); b) Intensity directivity patterns for $k a=8$ and amplitudes as in a); c) Power-gain function for $k a=8$ and radial modes amplitudes being equal to: $A_{0}=-0.21+0.32 i, A_{1}=1, A_{2}=-0.64 i$ (solid line), $A_{0}=0.38, A_{1}=1, A_{2}=0.64$ (dashed line), $A_{0}=0.38, A_{1}=1, A_{2}=0$ (dotted line). 
where $\gamma_{l}=\sqrt{k^{2}-\left(\mu_{l} / a\right)^{2}}$ is $l$-th mode partial wave number and $r_{l}$ is $l$-th mode total reflection coefficient $[2,4]$ :

$$
r_{l}=\sum_{n=0}^{N}\left|R_{l n}\right|^{2} \frac{\gamma_{n}}{\gamma_{l}}
$$

$R_{l n}$ being the transformation coefficient of incident $l$ th mode into reflected $n$-th mode.

\section{Results of numerical calculations. Conclusions}

We present here some typical graphs of the directivity patterns obtained by applying numerical methods to the formulae presented in Section 2.

The graphs have been obtained for $k a=8$, when besides the plane wave the first and second radial modes can propagate, thus the incident wave can be, in general, a superposition of all three component modes. Some efforts have been undertaken to match their amplitudes in a way to obtain approximately constant and significant value of energy radiation into a certain solid angle and very weak radiation beyond it. From among many analysed sets of amplitudes, we have chosen the following: $A_{0}=-0.21+0.32 i, A_{1}=1, A_{2}=-0.64 i$ as the best to obtain the required result (solid line in Fig. 2). These have been compared with the diffraction of the wave which components are in phase, having the same, as previously, modulus of amplitudes (dashed line in Fig. 2). In Figs. $2 a$ and $2 b$ the graphs drawn by dotted line represent the radiation of the incident wave in which the higher modes were neglected, which corresponds to plane wave approximation. In Fig. $2 \mathrm{c}$ only the highest mode $(l=2)$ has been neglected, as the values obtained for forward radiation in the plane wave approximation were too big to display them on the same figure with other data.

In fact many more graphs have been analysed, that led us to the following conclusions:

- the directivity patterns of acoustic pressure, intensity and power-gain function depend strongly on modulus and phases of the modes amplitudes;

- there is a possibility of constructing a source radiating only into a certain solid angle by matching complex amplitudes of specific modes;

- in the presence of higher-order modes the plane wave approximation can lead to significant errors.

\section{References}

[1] Bolleter, U. and Crocker, M.J., Theory and measurement of modal spectra in hard-walled cylindrical ducts. J. Acoust. Soc. Amer. 51 (1972), 1439.

[2] Wajnshtejn, L. A., The theory of diffraction and the factorization method. Generalised Wiener-Hopf technique. Golem 1969.

[3] Snakowska, A., The acoustic far field of an arbitrary Bessel mode radiating from the semi-infinite unflanged cylindrical wave-guide (to be published in Acustica).

[4] Snakowska, A., The energy distribution in the far field of an arbitrary Bessel mode radiating from the semi-infinite unflanged cylindrical wave-guide (to be published in Archives of Acoustics). 